\title{
Os Movimentos De Política Criminal - Direito Penal Mínimo
}

Fernanda De Castro Nakamura

\section{RESUMO}

O presente trabalho tem por escopo analisar o movimento de política criminal denominado direito penal mínimo, sob o enfoque da Constituição e do direito penal. Dessa forma, busca-se durante o trabalho adequar o disposto na Constituição, e no Direito Penal assim como no Processo Penal à realidade dos dias atuais, demonstrando, assim, o entendimento dos tribunais quanto a esse tema.

Palavras chave: Direito penal mínimo; Princípios; Bem jurídico penal; Constituição.

\begin{abstract}
The Movements of Criminal Policy - Minimal Criminal Law

The present work aims to analyze the movement of criminal policy called minimal criminal law under the focus of the Constitution and the criminal law. Thus this work seeks to adequate the norms stated in the Constitution and in the Criminal Law as well as in the Criminal Procedural Law to the current reality demonstrating the understanding and opinion of the high courts regarding this topic.
\end{abstract}

Keywords: minimal criminal law; principles; criminal legal good; Constitution

\section{Introdução}

Atualmente a preocupação com o combate à criminalidade, assim como a falência do sistema prisional, dentre outros fatores, traz à tona a discussão sobre a aplicação de um Direito Penal máximo ou de um Direito Penal mínimo.

Por um lado tem-se a criminalização de todas as condutas que possam trazer um mal para a sociedade, não se preocupando tanto com a relevância dos bens jurídicos a serem tutelados. Por outro lado tem-se a criminalização de certas condutas levando em consideração a relevância do bem jurídico a ser tutelado e qual a importância deste para a sociedade.

Sob esses dois paradigmas, deve-se levar em conta a situação histórica de uma sociedade e os valores primados por esta.

Dessa forma, o conceito de bem jurídico assume inteira importância, visto que este conceito vai se aperfeiçoando e se amoldando sempre em conformidade com as necessidades históricas de uma sociedade.

Os valores dispostos dentro da Carta Constitucional e o Estado Democrático de Direito primam pelos valores fundamentais da sociedade, tendo como base a vivência pacífica do ser humano e todos os valores inerentes a este.

Assim, dentro do exposto acima, o presente trabalho tem por escopo, delimitar o conceito de bem jurídico penal, tendo em vista a natureza dinâmica do direito, demonstrar o papel da Constituição e dos princípios dentro do direito penal mínimo e, também qual é o entendimento dos tribunais a respeito desse movimento de política criminal. 


\section{Conceito De Bem Jurídico Penal}

Primeiramente cabe dispor que não existe um conceito certo e definido de bem jurídico penal, uma vez que este sempre se amolda às circunstâncias históricas de uma determinada sociedade em um dado momento histórico.

Segundo Jorge de Figueiredo Dias, a noção de bem jurídico jamais será convertida em um conceito fechado ${ }^{1}$, pois este sempre estará atrelado à constante modificação na valoração dos bens jurídicos de acordo com as mudanças sociais ${ }^{2}$.

Essa valoração leva a criminalização ou descriminalização de condutas $^{3}$, servindo de base para fixação de penas, que podem ser mais brandas ou não, e, também, a determinação de uso das regras processuais de acordo com a gravidade dos delitos, contribuindo, também, para a construção legislativa ${ }^{4}$.

Nesse contexto, cabe dizer que as mudanças sociais vão surgindo conforme a sociedade vai se modernizando suscitando "ao direito penal problemas novos e incontornáveis que não podem ser camuflados"

A evolução histórica da "teoria do bem jurídico e o modelo de crime como ofensa a um dado bem jurídico afirmaram-se ao longo do tempo, como critérios de delimitação não só da matéria de incriminação, como dos próprios contornos da respectiva tutela"6.

Foi a partir do século XX que o conceito de bem jurídico penal passou a ser tomado como “expressão de um interesse, da pessoa ou da comunidade, na manutenção ou integridade de um certo estado, objeto ou bem em si mesmo socialmente relevante e, por isso, juridicamente reconhecido como valioso", , a partir do reconhecimento de disposições prévias à legislação penal que se encontram contidas no texto constitucional sob a égide do Estado Democrático de Direito.

\footnotetext{
${ }^{1}$ DIAS, Jorge de Figueiredo. Questões fundamentais de direito penal revisitadas. São Paulo: Revista dos Tribunais, 1999. p. 62.

${ }^{2}$ PRADO, Luiz Regis. Bem jurídico penal e constituição. 2.ed. São Paulo: Editora Revista dos Tribunais, 1997. p.41.

${ }^{3}$ PASCHOAL, Janaína Conceição. Constituição, criminalização e direito penal mínimo. São Paulo: Editora Revista dos Tribunais, 2003. p.18.

${ }^{4}$ PASCHOAL, op. cit., p.49.

${ }^{5}$ DIAS, Jorge de Figueiredo apud SOUZA, Paulo Vinicius Sporleder de. Bem jurídico penal e engenharia genética humana: contributo para compreensão dos bens jurídicos supra-individuais. São Paulo: Revista dos Tribunais, 2004. p. 112.

${ }^{6}$ BECHARA, Ana Elisa Liberatore S. O rendimento da teoria do bem jurídico penal no direito penal atual. Ibccrim Revista Liberdades, n. 1, p. 16-29, maio/agosto 2009 . Disponível em: <http://www.ibccrim.org.br/site/revistaLiberdades/_pdf/01/artigo1.pdf>.p. 16.

${ }^{7}$ DIAS, Jorge de Figueiredo, op. cit, p. 63.
} 
A Constituição, como norma jurídica suprema, se revela como um instrumento capaz de trazer os bens jurídicos dignos de tutela traçando quais desses bens devem ou não devem ser inseridos no contexto de proteção penal ${ }^{8}$.

Sob esse prisma, o bem jurídico penal faz parte dos valores fundamentais contidos no texto constitucional devendo ser analisado sempre com vistas ao desenvolvimento social ${ }^{9}$.

Atualmente, a "influência da evolução social sobre o atual desenvolvimento do direito penal gera uma tendência de dissolução do conceito de bem jurídico", pois além da análise dos bens jurídicos individuais passa-se a análise dos bens jurídicos supra-individuais.

Esses últimos fazem parte dos progressos alcançados em matéria penal como, por exemplo, direito penal econômico, direito penal do ambiente, direito penal secundário ou econômico social, mostrando "perfeitamente que a tarefa, sendo dificil, não é de cumprimento impossível"10.

Além disso, podem ser “(re)interpretados num plano maior de abstração, em sentido pessoal, haja vista que, em última análise, tudo o quanto é compreendido pela sociedade diz respeito a indivíduos concretos"11.

$\mathrm{O}$ conceito de bem jurídico utilizado até metade do século XX (critério de crítica e limitação à intervenção punitiva do legislador) passou a ser utilizado para "justificar e exigir a intervenção do direito penal, vale dizer, para reclamar a tutela penal, em vez de operar seu filtro"12.

Assim, são criados "novos bens jurídicos que certamente seriam mais bem protegidos em outros ramos do direito, de forma a evitar uma inflação penal como a que já se vê nos dias de hoje",13, e também, criam-se normas penais que tutelam "situações que não podem receber a denominação de bens jurídicos em sentido restrito" $"$.

Levando em consideração que o conceito de bem jurídico encontra-se indissociavelmente ligado à evolução histórica de uma sociedade, é cabível dispor que é necessário estabelecer uma separação nítida entre os bens jurídicos dignos de tutela e os bens jurídicos que não merecem a referida tutela em determinado momento histórico.

É preciso, ainda, verificar a subsistência da teoria do bem jurídico como critério negativo de delimitação de intervenção do direito penal ${ }^{15}$. Claus Roxin esclarece que no contexto de um Estado Democrático de Direito, "as normas penais apenas podem perseguir a finalidade de assegurar aos

\footnotetext{
${ }^{8}$ Cf. HASSEMER, Winfried apud BECHARA, op. cit., p.20.

${ }^{9}$ BECHARA, op. cit., p. 21.

${ }^{10}$ DIAS, Jorge de Figueiredo apud SOUZA, op. cit., p. 136.

${ }^{11}$ BECHARA, op. cit., p. 25.

${ }^{12}$ Id., ibid., p. 21.

${ }^{13}$ Id., ibid., p. 22.

${ }^{14}$ Id., ibid., p. 22.

${ }^{15}$ Id., ibid., p. 22.
} 
cidadãos uma coexistência livre e pacífica, garantindo o respeito aos direitos fundamentais de todos" $" 16$

Ainda, de acordo com o referido autor, o Estado deve garantir penalmente as condições individuais necessárias para tal coexistência, tais quais vida, a integridade física e o patrimônio e, também, as instituições estatais indispensáveis para tal fim como o sistema financeiro, a administração da justiça e o sistema fiscal ${ }^{17}$.

Os bens jurídicos se revelam, desse modo, como "realidades ou fins necessários para uma vida social livre e segura que garanta os direitos humanos fundamentais dos indivíduos, ou para o funcionamento do sistema estatal voltado à consecução de tais finss" ${ }^{\text {"18 }}$, salientando que esses bens são criados pelo legislador.

Sobre esse ponto existem alguns parâmetros gerais que servem de limites oponíveis ao legislador na criação de bens jurídicos, são alguns deles: a) a mera delimitação da finalidade da lei não constitui um bem jurídico; b) a lesão da própria dignidade não supõe a lesão de um bem jurídico; c) a mera ilicitude moral não basta para justificar uma disposição penal, exigindo-se a lesão ou perigo de lesão ao bem jurídico; d) as leis penais simbólicas que perseguem fins extrapenais não se servem de proteção aos bens jurídicos; e) as abstrações inapreensíveis não poderiam constituir bens jurídicos, dentre outros ${ }^{19}$.

Como complemento, salienta-se que ao Direito Penal cabe somente a tutela de bens relevantes para sociedade, sendo estes necessários à conservação desta, podendo determinar, também, a relevância das lesões e a aplicação da sanção penal a estas ${ }^{20}$.

Para que haja uma correta compreensão do bem jurídico no âmbito de um sistema aberto de princípios e regras, "baseado em uma sociedade pluralista na qual os valores se pautam no mundo de vida de cada um" ${ }^{21}$, deve-se atentar para os integrantes da comunicação que buscam atingir a auto-realização social em um espaço de possibilidades irrestritas de entendimento ${ }^{22}$.

Nesse sistema, o bem jurídico irá adquirir “contornos mais públicos”, porém continuará a representar " o padrão crítico irrenunciável pelo qual se deve aferir a observância da função e, conseqüentemente, a legitimação do direito penal em cada caso concreto",23.

\footnotetext{
${ }^{16}$ Cf. ROXIN, Claus apud BECHARA, op. cit., p. 24.

${ }^{17}$ Id., ibid., p. 24.

${ }^{18}$ Id., ibid., p. 24.

${ }^{19}$ BECHARA, op. cit., p. 25.

${ }^{20}$ PASCHOAL, op.cit., p.51.

${ }^{21}$ BECHARA, op. cit., p. 26

${ }^{22}$ Id., ibid., p. 26.

${ }^{23}$ Id., ibid., p. 26.
} 


\section{Constituição Federal E Direito Penal}

A Constituição dentro do campo do direito penal tem como objetivo primordial limitar o ius puniendi estatal, de forma negativa ou positiva, fixando-lhe as bases e os limites ${ }^{24}$.

No entanto, à Constituição não cabe somente o poder de limitação. Além de limitar, esta deve, também, fundamentar o Direito Penal, de modo a impedir a criminalização de certas condutas, ou seja, o texto constitucional traz as situações que merecem ser tratadas pelo legislador penal.

A Carta Constitucional deve ser o fundamento do Direito Penal, não um limite, sempre encerrando um bem jurídico constitucional em uma relação de reciprocidade, protegendo os bens jurídicos fundamentais ${ }^{25}$.

Colocada diante de situações de emergência ou de aparente emergência, a Constituição deve ser tomada como uma propulsora, ensejando questionamentos relativos ao descumprimento de uma indicação, ou determinação constitucional de criminalização ${ }^{26}$.

Nesse sentido, é colocado ao legislador um indicador do que deve ser criminalizado, não podendo este deixar de observar certas determinações expressas de criminalização, uma vez que constituem uma obrigatoriedade ${ }^{27}$.

As breves disposições colocadas acima atuam no sentido de se buscar um Direito Penal mínimo, que não conviva com uma "Constituição que traz, em seu bojo, necessidades automáticas

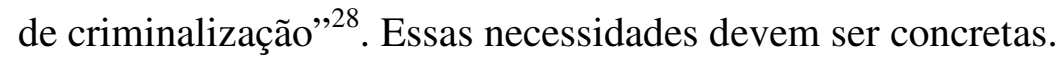

Tal afirmação é destacada por Domenico Pulitano, citado por Janaina da Conceição Paschoal, que reputa "insolúvel o conflito verificado entre os direitos fundamentais como instrumentos de garantia contra o Estado e os direitos fundamentais como fundamento e, conseqüientemente, propulsor do direito punitivo desse mesmo Estado"29.

Sob esse prisma tem-se que o Direito Penal mínimo deve pautar-se na necessidade efetiva e não meramente formal da tutela penal. A realização do direito penal mínimo independe da interpretação de determinações constitucionais expressas de criminalização restritivamente. A tipificação constitucional deve ser tomada de forma possível, possibilitando ao legislador ordinário o questionamento acerca de sua necessidade e utilidade no cenário social, como ocorre nas hipóteses de indicação de criminalização ${ }^{30}$.

\footnotetext{
${ }^{24}$ QUEIROZ, Paulo de Souza. Do caráter subsidiário do direito penal: lineamentos para um dirieto penal mínimo. 2.ed. Belo Horizonte: Del Rey, 2002. p. 59.

${ }^{25}$ PASCHOAL, op. cit., p.71.

${ }^{26}$ Id., ibid., p. 71.

${ }^{27}$ PASCHOAL, op. cit., p.72.

${ }^{28}$ Id., ibid., p. 77.

${ }^{29}$ Id., ibid., p. 78.

${ }^{30}$ Id., ibid., p. 69.
} 


\section{$3 \quad$ Direito Penal Mínimo: Princípios}

É sabido que o direito penal mínimo contém alguns princípios, sendo estes: o principio da insignificância, da intervenção mínima, da fragmentariedade, da subsidiariedade e da dignidade da pessoa humana.

\subsection{Princípio da insignificância}

Quanto ao aspecto histórico desse princípio, cabe salientar desde já, que existem divergências doutrinárias.

Alguns doutrinadores dizem que o princípio da insignificância surgiu com as crises sociais advindas das duas grandes guerras mundiais, proporcionando, assim, excessivo desemprego que aliado a outros fatores deram margem aos pequenos furtos, os chamados "crimes de bagatela" 31 .

Outros doutrinadores dizem ainda, que os chamados "crimes de bagatela" surgiram no direito romano, onde, também, não se dava muita importância aos pequenos furtos considerados irrelevantes ${ }^{32}$.

No entanto, tendo ou não nascido no direito romano ou no pós-guerra, o principio da insignificância delineou-se através dos tempos, aliado com o principio da legalidade, limitando seus desígnios criminalizadores ${ }^{33}$.

Atualmente tem-se a permissão de uma construção legislativa no sentido de não criminalizar condutas ou bens considerados irrelevantes à sociedade, delineando condutas que não necessitam da atuação penal, de modo a evitar um grande número de processos que poderiam ser resolvidos pelos outros ramos do direito.

Em face desse princípio leva-se em consideração que qualquer lesão jurídica admite, em tese, que se afaste a tipicidade pela aplicação do princípio da insignificância, uma vez que um "bem jurídico pode não ser atingido (o perigo de lesão é mera abstração) ou ser atingido perifericamente apenas em mínima intensidade, grau e extensão".

Depreende-se, ainda, que o dano produzido é tão insignificante que conseqüentemente haverá o desvalor do resultado sem nenhuma significação penal, “que seja ipso facto, desnecessário, que não se justifique, dada a evidente desproporcionalidade, o extremado castigo, visto que se mantém inatingido, ileso, por assim dizer, o núcleo do bem jurídico tutelado ${ }^{34}$.

\footnotetext{
${ }^{31}$ SANTOS, Maurício Macêdo dos; SÊGA, Viviane Amaral. Sobrevivência do princípio da insignificância diante das disposições da Lei 9099/95 . Jus Navigandi, Teresina, ano 4, n. 46, out. 2000. Disponível em: <http://jus2.uol.com.br/doutrina/texto.asp?id=950>. Acesso em: 17 mar. 2008. p.1.

${ }^{32}$ SANTOS; SÊGA, op. cit., p.1.

${ }^{33}$ Id., ibid., p.1.

${ }^{34}$ QUEIROZ, op. cit., p. 99.
} 
Ademais, é certo que não existe técnica legislativa pronta e acabada a ponto de "excluir a possibilidade de que, em alguns casos particulares, possam ficar fora da ameaça penal certas condutas que não apareçam como merecedoras de pena"35.

A redação do tipo legal requer a inclusão de prejuízos graves à ordem jurídica e social, mas não pode impedir que sejam inseridos em seu âmbito casos mais leves, que não representam nenhuma significação social ${ }^{36}$.

Como exemplo disso, pode-se obter do texto legal que a vida não detém proteção absoluta na medida em que o próprio Código Penal admite a supressão legal da vida do nascituro sempre que a gravidez resulte de estupro (Código Penal, art. 128, II); não tutela a liberdade sexual, se o ofendido opta por preservar a sua imagem e intimidade, porque a ação penal, nesses casos, é condicionada à representação ou à iniciativa do ofendido (Código Penal, art. 225) ${ }^{37}$.

De fato, a intervenção penal deve estar restrita a repressão de fatos que assumam magnitude penal incontrastável, devendo recusar curso aos chamados crimes de bagatela ${ }^{38}$.

Dessa forma, o princípio da insignificância serve como instrumento de interpretação restritiva, que tem como fundamento a concepção material do tipo penal, sendo possível alcançar por meio deste a descriminalização de condutas que, apesar de serem típicas, não atingem de forma relevante os bens jurídicos tutelados pelo Direito Penal ${ }^{39}$.

Por último, salienta-se que além de servir como instrumento de interpretação restritiva, o principio da insignificância serve também como instrumento que visa limitar a abrangência do tipo penal em relação às condutas mais gravosas, ou seja, tem-se um tratamento proporcional em relação à pena e ao crime ${ }^{40}$.

\subsection{Princípio da ofensividade (intervenção penal mínima)}

O Direito Penal, sob o enfoque do principio da ofensividade do fato, é visto como um instrumento de tutela dos bens representativos dos valores mais essenciais, mais caros para o desenvolvimento da personalidade do individuo. Tal enfoque diz respeito ao conteúdo e a missão do Direito Penal, que é o de proteção dos bens jurídicos.

A concepção de delito tida aqui implica necessariamente em uma conduta ofensiva, inserindo a preocupação da determinação dos limites racionais dentro dos quais o legislador pode, de forma

\footnotetext{
${ }^{35}$ Id., ibid., p. 98.

${ }^{36}$ Id., ibid., p. 98.

${ }^{37}$ Id., ibid., p. 95.

${ }^{38}$ QUEIROZ, op. cit., p. 100.

${ }^{39}$ PRADO, op. cit., p.80-81.

${ }^{40}$ Id., ibid., p. 81.
} 
legitima, antecipar a tutela penal, devendo ser esta ser concebida de forma fragmentária e subsidiária.

Sob essa ótica, o delito passa a ser concebido como um fato ofensivo típico, uma vez que, não há crime sem ofensa, lesão ou perigo concreto de lesão a um bem jurídico tutelado pela norma penal.

Em suma, tem-se que para a legitimação da intervenção estatal é imprescindível a prova concreta, efetiva, real da lesão ao bem jurídico.

A partir dessa dimensão, tem-se a presença de três juízos distintos: juízo de desvaloração da conduta, juízo de desvaloração do resultado jurídico e juízo de imputação objetiva.

O resultado jurídico tem que ser colocado nas exigências da tipicidade material, sendo desvalioso quando real ou concreto, transcendental, grave e intolerável ${ }^{41}$.

Nas palavras de Luiz Flávio Gomes, tal principio deve ser enfocado como critério limitador da intervenção penal, considerada esta em suas duas dimensões- subjetiva (o Estado é o único titular do ius puniendi) e objetiva (o Estado só pode agir na medida em que autorizado pelo ordenamento jurídico $)^{42}$.

Assim, na falta de uma dimensão normativa, que implica a presença dos três juízos distintos citados acima, leva a atipicidade do fato, pois se não houver ofensividade, não há tipicidade.

\subsection{Princípio da fragmentariedade}

Pelo principio da fragmentariedade entende-se que somente as condutas consideradas mais graves e perigosas praticadas contra bens juridicamente relevantes são merecedoras de sanção penal. Somente os bens jurídicos mais fundamentais para a convivência em sociedade serão protegidos diante dos ataques mais intoleráveis que possam vir a ofendê-los ${ }^{43}$.

Alessandro Baratta explica que a "fragmentação das áreas de tutela em cada ramo do direito depende não tanto da índole ou qualidade dos bens, mas principalmente da estrutura das diversas situações que lhes são prejudiciais e da qual se incumbem os diversos ramos do direito que concorrem entre si para preferir um ou outro com as técnicas próprias e específicas de tutela de cada qual" $" 44$.

\footnotetext{
${ }^{41}$ GOMES, Luiz Flavio. "Principio da ofensividade do fato". In. SCHMITT, Ricardo Augusto. Princípios penais constitucionais - direito e processo penal sob a luz da Constituição Federal. Salvador: Podivm. 2007. pp. 35-36.

${ }^{42}$ GOMES In: SCHMITT, op. cit., p. 36.

${ }^{43}$ SOUZA, op. cit., p. 150-151.

${ }^{44}$ BARATTA, Alessandro apud SPORLEDER, op. cit., p.162.
} 
Assim, "o princípio da fragmentariedade impõe uma tutela seletiva e, portanto, lacunosa do bem jurídico, que se limita à tipologia agressiva que se revele dotada de uma indiscutível relevância tanto em relação com a gravidade como em relação com a intensidade da ofensa"45.

Deve-se aferir a hierarquia dos bens jurídicos como "diferenciados modos de desvalor da conduta e do resultado, como, por exemplo, tentativa/consumação, dolo/culpa, perigo/dano, ação/omissão, são avaliados e ponderados com o fim de estabelecer uma correta composição dos tipos penais na legislação",46.

No exemplo dado por Claus Roxin: "maus-tratos não é qualquer tipo de dano à integridade corporal, senão somente um dano relevante; injuriosa em uma forma delitiva (...) a ameaça deve ser sensível para passar do umbral da criminalidade" $"$.

A função precípua do direito penal, levando em conta seu caráter fragmentário é a de se ocupar somente com as condutas consideradas mais capazes de ofenderem os bens jurídicos passíveis de serem convertidos em bens jurídicos penais ${ }^{48}$.

\subsection{Princípio da subsidiariedade}

Tendo liame com o principio da fragmentariedade, esse princípio, revela o Direito Penal como um sancionador extremo, atuando somente quando não houver outros ramos do direito que sejam capazes de solucionar o conflito.

O direito penal não produz um sistema único, “próprio de ilicitudes, fora ou além da ordem jurídica vigente, mesmo porque, (...) a ilicitude jurídica é uma só, do mesmo modo que um só, na sua essência, é o dever jurídico"49.

Inicialmente demarca fatos que já são extintos pela ordem jurídica extrapenal (constitucional, administrativa, civil, processual, etc) de forma explícita ou implícita, descrevendo aqui uma "ulterioridade lógica, não necessariamente cronológica" ${ }^{\text {, }}$, tratando-se aqui da subsidiariedade lógica.

Essa subsidiariedade do direito penal provém da unidade lógica do direito; da imposição político-criminal (tendo em vista a posição mais enérgica do direito penal dentro da ordem jurídica), sendo que a intervenção deste só será concreta quando houver afronta a "bens jurídicos fundamentais e para cuja repressão não bastem as sanções do ordenamento jurídico (ordinário-

\footnotetext{
${ }^{45}$ Id., ibid., p. 151.

${ }^{46}$ SOUZA, op. cit., p. 151.

${ }^{47}$ QUEIROZ, op. cit., p. 99.

${ }^{48}$ SOUZA, op. cit., p. 151.

${ }^{49}$ QUEIROZ, op. cit., p. 57.

${ }^{50}$ Id., ibid., p. 57.
} 
principal), demandando, enfim, um plus de gravidade proporcional à gravidade da lesão e à significação social" ${ }^{\prime 51}$, nesse patamar há a materialização da intervenção extraordinária-subsidiária do direito criminal.

O direito penal, nesse ponto, se caracteriza pela sua natureza secundária que é sempre exigida política e juridicamente do legislador ${ }^{52}$.

O bem jurídico e o ilícito procedem da Constituição do país e derivadamente na ordem infraconstitucional surgem como sistematização do ilícito constitucional-originário, tudo isso é a conseqüência da necessidade de conferir a estes efetiva proteção jurídica. O ilícito penal, por sua vez, está interligado com os demais ramos do direito pelo fato de o direito penal ser "o mais rigoroso e extremado modo de tutela jurídica"53.

Além da subsidiariedade lógica, aponta-se também a subsidiariedade política que considera o direito penal em face do próprio direito e a subsiariedade social que se conecta com a ordem social e o sistema global de controle ${ }^{54}$.

Em conformidade com a intervenção mínima, a intervenção do Direito Penal só é legítima quando não houver nenhum outro ramo do direito que se revele eficaz para determinado conflito, ou seja, quando houver ataques muito graves aos bens jurídicos. Quanto aos ataques mais leves, estes podem ser solucionados pelos outros ramos do direito ${ }^{55}$.

Concluindo, cabe dispor que a intervenção penal pressupõe: “a) utilização e efetivo funcionamento dos instrumentos primários de prevenção do comportamento desviado e ter ainda presente todo o aparato de controle social já existente; b) que tais instrumentos racionalmente utilizados não bastem para dita prevenção e controle; c) que possa o direito penal, subsidiando-os, concorrer, utilmente para redução a níveis toleráveis do fenômeno delitivo" ${ }^{, 56}$.

\subsection{Princípio dignidade da pessoa humana}

O principio da dignidade da pessoa humana encontra previsão na Constituição Federal, em seu art. 1, inciso III. Esse princípio não contém um conceito certo e determinado, tendo em vista a amplitude do seu significado e de sua dimensão valorativa.

Por ser dotado de imensa dimensão valorativa, é cabível definir o conceito de dignidade colocada no âmbito da epistemologia jurídica. A dignidade, na seara da epistemologia jurídica, se

\footnotetext{
${ }^{51}$ Id., ibid., p. 58.

${ }^{52}$ Id., ibid., p. 58.

${ }^{53}$ Id., ibid., p. 59.

${ }^{54}$ Id., ibid., p. 64.

${ }^{55}$ GOMES In: SCHMITT, op. cit., p. 67.

${ }^{56}$ Id., ibid., p. 70.
} 
configura como uma qualidade moral do homem, um valor espiritual e moral, que se encontra ligada aos conceitos de decência, decoro, honra e consciência do próprio valor, tendo de ser respeitada e considerada, sob pena de se negar a própria condição humana ${ }^{57}$.

Cabe dispor, ainda, que uma grande gama de direitos são imprescindíveis a esse conceito, tais como, o direito à vida, à igualdade, à integridade física e psíquica, à honra, dentre outros direitos fundamentais que encontram uma referencia valorativa no conceito de dignidade.

Em um mesmo sentido, salienta-se que a proibição da pena de morte, a integridade física e psíquica, a liberdade geral, dentre outras previsões constitucionais, refere-se ao valor essencial da dignidade humana.

Estabelecido quanto ao seu significado, passar-se-á a análise deste principio quanto aos seus efeitos.

Quanto aos efeitos, o princípio da dignidade humana tem duas funções, a saber: função limitadora e função prestacional ${ }^{58}$. A função limitadora dispõe sobre a limitação dada à atuação estatal, de modo que os órgãos públicos atuem respeitando a dignidade humana. Assim considera-se o ius puniendi estatal, visto que os órgãos de persecução criminal, em sua atuação, são limitados e balizados por esse principio.

Além da limitação dada à atuação estatal, tem-se, também, a limitação dada no âmbito da construção legislativa, ressaltando aqui que a atividade legiferante tem de atentar aos postulados desse principio não editando nenhuma previsão legal que seja supressiva ou restritiva da dignidade do homem.

Colocada no âmbito do direito penal mínimo, a limitação da atividade legiferante, reflete na intervenção mínima do Direito Penal, considerando a produção desnecessária de tipos penais, incriminando condutas e explorando casuisticamente fatos que, afetam de forma reflexiva, a dignidade humana. Tais fatos e condutas mesmo sendo graves e merecedores de reprimenda penal, devem ser vistos sob a ótica de outros ramos do direito ou até da realização de políticas públicas que se encontram no conteúdo programático da Constituição Federal.

Em suma, conforme o disposto acima, as condutas a serem criminalizadas ou tipificadas devem constituir um meio necessário de proteção ao bem jurídico lesado; caso existam outros meios que supram essa proteção ao bem jurídico, a lei penal e a insegurança jurídica podem representar uma ameaça à dignidade humana.

\footnotetext{
${ }^{57}$ Id. ibid., p. 284.

${ }^{58}$ Id. ibid., p. 295.
} 
A função prestacional consiste na promoção e realização da vida digna, refletindo assim no dever estatal de proteção da dignidade das pessoas. Tal função abarca a construção das leis penais, visto que o legislador deve criminalizar condutas que atentam bens jurídicos relevantes.

Nesse sentido a tutela de bens jurídicos relevantes, tais como a vida, a liberdade, a integridade física e psíquica do homem, dentre outros, fazem parte do exercício da função prestacional da dignidade humana, uma vez que se promove a dignidade humana através da preservação dos bens jurídicos relevantes.

Ainda, dentro da função prestacional, cabe ao Estado a adoção de uma postura positiva, conformadora, que seja capaz de realizar atos e criar normas que suprimam todo e qualquer empecilho à concretização da dignidade humana ${ }^{59}$.

Dessa forma, tendo-se em vista a realidade da violência e criminalidade, cabe ao Estado a inclusão social e o desenvolvimento de políticas públicas capazes de suprir as condições básicas da dignidade humana, incluindo, aqui, as atividades voltadas para segurança pública.

A organização do Estado voltada para a prática de uma segurança pública eficaz e séria se configura no cumprimento da promoção e garantia de vida digna a todos os homens.

No tocante à sanção penal, especificamente o uso da pena privativa de liberdade, deve-se primar pela aplicação da justa duração da pena assim como a sua correta individualização.

\section{Descriminalização E Despenalização}

Descriminalização significa subtrair da estrutura constituidora do crime, tal qual, fato típico, antijurídico e culpável, um de seus elementos, resultando na redução do fato a um evento não cominado com a sanção penal, não sendo esta a conseqüência de sua prática.

Configura-se, também, como técnica de processo legislativo embasado em razões de política criminal de extinção de modelo de conduta pela superação, através de qualquer meio, de sua estrutura típica, ilícita ou pela culpabilidade ${ }^{60}$.

Despenalizar, por seu turno, configura-se na elevação das permissividades jurisdicionais, face ao deferimento de prerrogativas de utilização, mais especificamente do perdão judicial.

Dessa forma, a conduta típica continuaria a existir, mas se utilizaria certa prudência por parte do juiz ao tornar isento o autor de um crime considerado irrelevante ${ }^{61}$.

\footnotetext{
${ }^{59}$ GOMES In: SCHMITT, op. cit. p. 296.

${ }^{60}$ FIGUEIRA JUNIOR, Joel Dias; RIBEIRO LOPES, Mauricio Antonio. Comentários à lei de juizados especiais cíveis e criminais. São Paulo: Editora Revista dos Tribunais, 1995. p. 264.

${ }^{61}$ Id. ibid., p. 265.
} 
As breves considerações a respeito dos conceitos de descriminalização e despenalização exercem grandes reflexos no direito penal mínimo, uma vez que se visa punir veementemente as condutas que possam causar grandes riscos e danos à sociedade.

Ainda dentro da seara do direito penal mínimo, salienta-se o instituto dos Juizados Especiais Criminais, que volta sua preocupação somente para os delitos de menor relevância para a sociedade.

\section{$5 \quad$ Direito Penal Mínimo: Juizados Especiais Criminais}

A criação dos Juizados Especiais Criminais permitiu um exame mais específico e proporcional a respeito das infrações de menor potencial ofensivo. Assim, tem-se um tratamento diferenciado e compatível com a natureza dessas infrações, sendo estas tratadas de forma mais célere e prática.

Além do mais, tal instituto trouxe consigo a construção de um modelo atual de resolução das questões judiciais, uma vez que contém em si os critérios da oralidade, simplicidade, informalidade, economia processual e celeridade, buscando a composição e a transação em um primeiro momento, e a suspensão condicional do processo em um segundo momento. Sob a ótica do Direito Penal mínimo, esse formato de Justiça se apresenta relevante, uma vez que se dá um tratamento mais específico e cuidadoso com condutas que não apresentam grandes riscos à sociedade.

Percebe-se assim, que há uma maior preocupação com a reparação dos danos sofridos pela vítima e pela aplicação da pena não-privativa da liberdade, em face da menor ofensividade do delito.

Ademais, deve-se levar em conta que além de não afastar a impunidade de certos delitos, há proporcionalidade no tratamento destes em relação aos considerados de maior relevância e periculosidade.

\section{Jurisprudência}

$\mathrm{O}$ entendimento dos tribunais quanto à aplicação do direito penal mínimo, pauta-se em quatro elementos que devem fundamentar essa aplicação, sendo estes: a mínima ofensividade da conduta do agente; a ausência total da periculosidade da ação; o ínfimo grau de reprovabilidade do comportamento; e a inexpressividade da lesão jurídica ocasionada. Assim ante a ausência de um desses elementos a aplicação do direito penal mínimo se mostra incabível.

Para ilustrar, seguem alguns julgados a respeito do tema:

RECURSO ESPECIAL. FURTO. VALOR SUBTRAÍDO IRRISÓRIO. GRAVIDADE DO FATO. PRINCÍPIO DA 


\section{INSIGNIFICÂNCIA. CONDENAÇÃOO. PRESCRIÇÃ̃O DA PRETENSÃO PUNITIVA.}

1. O poder de resposta penal, positivado na Constituição da República e nas leis, por força do princípio da intervenção mínima do Estado, de que deve ser expressão, "(...) só vai até onde seja necessário para a proteção do bem jurídico. Não se deve ocupar de bagatelas" (Francisco de Assis Toledo, in Princípios Básicos de Direito Penal).

2. A incidência, contudo, do princípio da insignificância requisita a mínima ofensividade da conduta do agente, a nenhuma periculosidade social da ação, o reduzido grau de reprovabilidade do comportamento e a inexpressividade da lesão jurídica provocada, como na lição do Excelso Supremo Tribunal Federal, circunstâncias induvidosamente inocorrentes no caso de furto praticado em concurso de agentes, mediante escalada e rompimento de obstáculo com uso de "pé-de-cabra", por sujeito corruptor de menores e dado à prática de ações contrárias ao Direito, que, assim, subtrai estoque de pequeno estabelecimento. 3. Ultrapassado o lapso temporal extintivo de 2 anos (artigo 109, inciso V, combinado com os artigos 110 e 115, todos do Código Penal), contados do recebimento da denúncia, forçoso o reconhecimento da prescrição da pretensão punitiva, modalidade retroativa.

4. Recurso especial provido, para reforma do decisum absolutório, com conseqüente extinção da punibilidade dos crimes pela prescrição da pretensão punitiva.

(REsp 770.899/RS, Rel. Ministro HAMILTON CARVALHIDO, SEXTA TURMA, julgado em 09.12.2005, DJ 06.02.2006 p. 399)

\section{HABEAS CORPUS. PENAL. DESCAMINHO. PRINCÍPIO DA INSIGNIFICÂNCIA. \\ INAPLICABILIDADE. HABITUALIDADE CRIMINOSA.}

1. A missão do Direito Penal moderno consiste em tutelar os bens jurídicos mais relevantes. Em decorrência disso, a intervenção penal deve ter o caráter fragmentário, protegendo apenas os bens jurídicos mais importantes e em caso de lesões de maior gravidade;

2. "O princípio da insignificância - que considera necessária, na aferição do relevo material da tipicidade penal, a presença de certos vetores, tais como (a) a mínima ofensividade da conduta do agente, (b) a nenhuma periculosidade social da ação, (c) o reduzidíssimo grau de reprovabilidade do comportamento e (d) a inexpressividade da lesão jurídica provocada" (HC 84.412, STF, Rel.

Min. Celso de Mello, decisão publicada no DJU de 2/8/2004); 3. Não obstante o baixo valor dos impostos devidos constituir condição necessária à aplicação do princípio, não se mostra, todavia, suficiente para tanto; não se deve olvidar que as 
condutas praticadas, na medida em que a ação ora em exame não se mostra isolada, mas constitui meio habitual para recomposição de estoques comerciais, mostram-se bastante reprováveis sob o ponto de vista de sua repercussão social, tornando inaceitável a complacência do Estado para com tal comportamento;

4. Ordem denegada.

(HC 44.986/RS, Rel. Ministro HÉLIO QUAGLIA BARBOSA, SEXTA TURMA, julgado em 06.09.2005, DJ 07.11.2005 p. 395)

\section{RECURSO ESPECIAL. PENAL. FURTO. COMPORTAMENTO SOCIALMENTE REPROVÁVEL. PRINCÍPIO DA INSIGNIFICÂNCIA. INAPLICABILIDADE.}

1. A missão do Direito Penal moderno consiste em tutelar os bens jurídicos mais relevantes. Em decorrência disso, a intervenção penal deve ter o caráter fragmentário, protegendo apenas os bens jurídicos mais importantes e em casos de lesões de maior gravidade.

2. O princípio da insignificância considera necessária, na aferição do relevo material da tipicidade penal, a presença de uma mínima ofensividade da conduta do agente, nenhuma periculosidade social da ação, reduzido grau de reprovabilidade do comportamento e inexpressividade da lesão jurídica provocada (precedentes HC 84.412, STF, Rel. Min. Celso de Mello).

3. Se parece claro que o furto de uns "poucos litros de água potável" não ensejaria o acionamento da máquina jurídico-penal do Estado, pela inexpressividade da lesão jurídica provocada, por outra volta, não se deve olvidar que tal conduta se mostra bastante reprovável, sob o ponto de vista de sua repercussão social.

Inaceitável a complacência do Estado para com aqueles que, em condições de arcar com as respectivas contraprestações, venham a usufruir irregularmente e de forma gratuita de bens e serviços públicos, em detrimento da grande maioria da população.

4. Recurso parcialmente conhecido e provido.

(REsp 406.986/MG, Rel. Ministro HÉLIO QUAGLIA

BARBOSA, SEXTA TURMA, julgado em 23.11.2004, DJ 17.12.2004 p. 600)

\section{CONCLUSÃO}

Hodiernamente, em face da operacionalidade do direito penal na busca da garantia de segurança dos indivíduos em sociedade, faz com que certos parâmetros gerais sejam analisados com relação a determinação dos bens jurídicos a seres tutelados penalmente. 
A necessidade de sopesamento de bens jurídicos é necessário na medida em que visa impedir uma indevida intervenção penal.

A Constituição, nessa monta, se caracteriza como instrumento fundamental para definir os limites e as bases do direito penal em face de sua supremacia no ordenamento jurídico. É nesta que se encontram os parâmetros capazes de definir quais bens jurídicos são merecedores de tutela penal. Apesar de o texto constitucional estabelecer limites e bases para o direito penal, é cabível dispor que o caso concreto em sua essência é que irá trazer os elementos indispensáveis para a tutela de um determinado bem jurídico. O caso concreto interligado com os princípios norteadores do direito penal, com os conceitos de ilícito penal e de bem jurídico é que irá determinar "o juízo sobre a utilidade ou lesividade, a licitude ou ilicitude de um comportamento"62.

Nesse panorama destaca-se ainda que a "ordem jurídica como um todo contribui para a formação desses direitos de intervenção, que harmonizam a liberdade individual com a necessidade social"63. Isto é, o Estado não pode utilizar de nenhum tipo de coação para manter a ordem social, pelo contrário deve conformar a proteção com a liberdade da pessoa ${ }^{64}$.

No contexto do Estado Democrático de Direito, cabe ao direito penal uma dupla função geral: a primeira diz se perfaz em uma prevenção geral de delitos e a segunda em uma prevenção geral de penas arbitrárias ou desproporcionadas ${ }^{65}$.

A concepção do direito penal como mecanismo de tutela dos direitos fundamentais não pode levar à falsa ilusão de que todos, exatamente todos os bens jurídicos devem estar abarcados por este ramo do direito ${ }^{66}$.

Nessa monta, a utilização do direito penal mínimo está atrelada ao perfazimento de condutas irrelevantes, de mínima significação social. Entretanto a definição de bens jurídicos penalmente tutelados vai ganhando maior amplitude na medida em que surge os bens jurídicos supraindividuais que fazem parte dos indiscutíveis progressos da humanidade, e que somente serão legítimos se servirem ao desenvolvimento pessoal dos cidadãos ${ }^{67}$.

A intervenção penal somente será legítima se "a soma das violências - delitos, vinganças e castigos arbitrários - que está em condições de prevenir é superior às violências constituídas por delitos não prevenidos e pelas penas penas estabelecidas para estas" ${ }^{\text {,68 }}$, ou seja, o direito penal só se

\footnotetext{
${ }^{62}$ ROXIN, Claus. Política criminal e sistema jurídico penal. Rio de Janeiro: Renovar, 2000. p. 53.

${ }^{63}$ Id., ibid., p. 52.

${ }^{64}$ BECHARA, op. cit., p. 26.

${ }^{65}$ QUEIROZ, op. cit., p. 53.

${ }^{66}$ Cf. Id., ibid., p.53.

${ }^{67}$ BECHARA, op. cit., p. 23.

${ }^{68}$ FERRAJOLI, Luigi apud QUEIROZ, op. cit., p. 53.
} 
faz totalmente eficaz e útil diante de delitos que assumam incontrastáveis danos à sociedade em geral.

\section{REFERÊNCIAS BIBLIOGRÁFICAS}

AMARAL, Alberto Carvalho. $O$ conflito entre dois modelos de política criminal contraditórios. $O$ eficientismo e o garantismo. Jus Navigandi, Teresina, ano 12, n. 1700, 26 fev. 2008. Disponível em: <http://jus2.uol.com.br/doutrina/texto.asp?id=10985>. Acesso em: 04 mar. 2008.

BECHARA, Ana Elisa Liberatore S. O rendimento da teoria do bem jurídico penal no dirieto penal atual. Ibccrim - Revista Liberdades, n. 1, p. 16-29, maio/agosto 2009. Disponível em: $<$ http://www.ibccrim.org.br/site/revistaliberdades/_pdf/01/artigo1.pdf>.

DIAS, Jorge de Figueiredo. Questões fundamentais de direito penal revisitadas. São Paulo: Revista dos Tribunais, 1999.

FIGUEIRA JUNIOR, Joel Dias. RIBEIRO LOPES, Mauricio Antonio. Comentários à lei de juizados especiais cíveis e criminais. São Paulo: Editora Revista dos Tribunais, 1995.

OLIVEIRA, André Abreu de. O Direito Penal mínimo e sua aplicação no atual Estado Brasileiro. Boletim Jurídico, Uberaba/MG, $\mathrm{n}^{\mathrm{o}} 188 . \quad$ Disponível em: <http://www.boletimjuridico.com.br/doutrina/texto.asp?id=1436> Acesso em: 25 fev. 2008.

PASCHOAL, Janaína Conceição. Constituição, criminalização e direito penal mínimo. São Paulo: Editora Revista dos Tribunais, 2003.

PRADO, Luiz Regis. Bem jurídico e constituição. 2.ed. São Paulo: Editora Revista dos Tribunais, 1997.

QUEIROZ, Paulo de Souza. Do caráter subsidiário do direito penal: lineamentos para um direito penal mínimo. 2. ed. Belo Horizonte: Del Rey, 2002.

ROXIN, Claus. Política criminal e sistema jurídico penal. Rio de Janeiro: Renovar, 2000.

SANTOS, Maurício Macêdo dos; SÊGA, Viviane Amaral. Sobrevivência do princípio da insignificância diante das disposições da Lei 9099/95 . Jus Navigandi, Teresina, ano 4, n. 46, out. 2000. Disponível em: <http://jus2.uol.com.br/doutrina/texto.asp?id=950>. Acesso em: 17 mar. 2008.

SCHMITT, Ricardo Augusto. Princípios penais constitucionais - direito e processo penal à luz da constituição federal. Bahia: Salvador: Editora Podivm, 2007.

SOUZA, Paulo Vinicius Sporleder de. Bem jurídico penal e engenharia genética humana: contributo para compreensão dos bens jurídicos supra-individuais. São Paulo: Revista dos Tribunais, 2004. 